\title{
Epidemiological Study on Spray Paint Workers
}

\author{
Varghese $\mathrm{P} \mathrm{R}^{1^{*}}$, Zubair $\mathrm{M}^{2}$, Saji $\mathrm{K} \mathrm{G}^{3}$ and Alex George \\ ${ }^{1}$ Jubilee Centre for Medical Research, Thrissur, Kerala, 680005, India \\ ${ }^{2}$ Departments of Zoology, University of Calicut, Kerala, 673635, India \\ ${ }^{3}$ Department of Zoology, St Aloysius College, Elthuruth, Thrissur, Kerala, India
}

\begin{abstract}
Spray paint is an aerosol product designed to be dispensed as a fine mist. Compared to conventional brush methods of painting, spray painting is faster and provides a more uniform application. While industrial spray painting relies on special air compressors that break the paint particles into a fine mist, commercial spray paints are self-contained aerosol cans that use liquefied gasses to atomize the paint. The 72 workers interviewed were males and were from Thrissur district, Kerala state, India. The $72 \%$ had more than 10 years of exposure at the time of interview. BMI study shows that majority of them were within the desirable limit. Thirty six percentages were alcoholics and 22\% smokers. Many workers reported symptoms like irritant to skin/eyes/nose (39\%), head ache (33\%), fatigueness/ tiredness (31\%), persistent cough (28\%), breathlessness during work (14\%), dizziness (14\%), burns to skin or eyes (14\%) and Wheezing (11\%). The study suggests that the workers in spray paint industry are at the risk of developing a lot of occupational health issues and proper precautions to be taken.
\end{abstract}

Keywords: spray paint workers, epidemiology, occupational hazards

\section{Introduction}

Since its birth in the 1950s, the spray paint industry has enjoyed considerable success but has also met with many challenges. In the late 1970s, legislators banned paints from using chlorofluorocarbon propellants (CFCs) since these solvents are thought to play in atmospheric ozone depletion. In the late 1990s, the California Air Resource Board (CARB) began imposing limits on the amount of Volatile Organic Compounds (VOCs) that can be used in spray paint. VOCs have been shown to contribute to air pollution. These regulatory mandates have dramatically affected the quality of spray paint formulations. In spite of these challenges, spray paints continue to be popular consumer commodities.

Paints have a higher percentage of solvents per volume. Spray Paint is an aerosol product designed to be dispensed as a fine mist. Compared to conventional brush methods of painting, it is faster and provides a more uniform application. While industrial spray painting relies on special air compressors that break the paint particles into a fine mist and commercial spray paints are self-contained aerosol cans that use liquefied gasses to atomize the paint. Pigments are also used in spray paint to provide color and opacity. White pigments such as titanium dioxide are used to scatter light and make the painted surface more opaque. Propellants are gasses that force the paint out of the can by expanding rapidly when the valve is opened. Gasses like butane and propane were used as propellants ${ }^{[1]}$.

The human costs are also potentially great; people working in paint manufacturing industries, painters and spray painters are exposed to an extensive variety of hazardous substances such as organic solvents, leadcontaining pigments and residual plastic monomers. These workers use gasoline or thinner as solvents. Hence, they constitute the high risk group for genotoxicity. Workers with this condition may suffer weakness, weight loss, insomnia, anemia, and pains in their muscles and joints. They can be irritants to the eye and the respiratory system and may result in sensitization of the worker ${ }^{[2,3]}$.

In the current Indian scenario, growing industrialization and urbanization have resulted in the emergence of a large number of workshops for spray painting to service used cars, two wheelers, refrigerators and small scale steel and wooden furniture in the secondary service sector.

The adverse health effects of spray painting are reported in this study. Coatings that spray painters apply can enter their bodies through the nose, mouth, and skin. From there they can enter the respiratory system, the digestive system, and the bloodstream. The ingestion of solvents in clinically significant amounts occurs very infrequently in the occupational setting. The rate of solvent uptake through the skin varies among workers due to the variation in skin thickness, skin perfusion, and presence of cuts or abrasions of the skin. Increased solvent absorption can occur when solvents are trapped between wet clothing and $\operatorname{skin}^{[4]}$. In short, organic solvents may be absorbed by workers either through the respiratory tract or the skin.

There are two primary occupational diseases associated with paint spray operations. These are painter's asthma and dermatitis ${ }^{[5,6]}$. The combination of different chemical solvents, pigments and other additives in paints that becomes airborne in spraying operations make it difficult to quantitative the risk based on a specific hazard assessment, although career spray painters tend to have a predisposition to these diseases. Long-term 
exposure to solvents has been reported to lead to chronic, irreversible brain damage, with intellectual impairment and decrements in performance, as well as mood disorders, demonstrated by neurobehavioral testing ${ }^{[7]}$. Electroencephalographic abnormalities have been reported, characterized primarily by a diffuse low wave pattern ${ }^{[8]}$.

\section{Materials And Methods}

This is an epidemiological study on spray paint workers. A specially designed questionnaire was used to know their personal, occupational and health related information. The study was conducted during January March 2014

Altogether 72 workers were interviewed. All of them were males and from Thrissur district of Kerala state, India. The questionnaires are analysed and the data is presented. The analysis is made based on year of exposure, age, personal habits like smoking, alcoholism and chewing, body mass index (BMI) and health related symptoms.

The following symptoms are included in the questionnaire.

Persistent cough

Breathlessness during work

Wheezing

Dizziness

Vomiting tendency
Diarrhoea

Burns to skin or eyes

Irritant to skin/eyes/nose

Fatigueness/ tiredness

Head ache

\section{Observations}

Seventy two spray paint workers were interviewed. All of them were males and from Thrissur district. They were working in furniture and automobile spray painting centers. Major number of them was in 31-40 age groups (Table 1). The years of exposure shows that they were in this profession for a longer period (Table 2). Seventy two percentages were of more than 10 years of exposure. BMI study shows that majority of them were within the desirable limit (Table 3). Thirty six percentages were alcoholics and $22 \%$ smokers. No chewers were reported.

Table 1. Age wise distribution of the spray paint workers

\begin{tabular}{|c|c|c|}
\hline Age group & Number & In percentage \\
\hline$<20$ & 2 & 2.5 \\
\hline $21-30$ & 20 & 28 \\
\hline $31-40$ & 30 & 42 \\
\hline $41-50$ & 10 & 14 \\
\hline $51-60$ & 8 & 11 \\
\hline$>61$ & 2 & 2.5 \\
\hline
\end{tabular}

Table 2. Duration of exposure in years

\begin{tabular}{|c|c|c|}
\hline Duration of exposure in years & Number & In percentage \\
\hline$<10$ & 20 & 28 \\
\hline $10-20$ & 30 & 42 \\
\hline$>20$ & 22 & 30 \\
\hline
\end{tabular}

Table 3. Body Mass index of the workers

\begin{tabular}{|l|c|c|}
\hline \multicolumn{1}{|c|}{ BMI } & Number & In percentage \\
\hline Thin & 4 & 6 \\
\hline Normal & 34 & 47 \\
\hline Over weight & 34 & 47 \\
\hline Obese & Nil & 0 \\
\hline
\end{tabular}

Many workers reported symptoms like irritant to skin/eyes/nose (39\%), head ache (33\%), fatigueness/ tiredness (31\%), persistent cough (28\%), breathlessness during work (14\%), dizziness (14\%), burns to skin or eyes (14\%), Wheezing (11\%) (Table 4).

Table 4. The main presenting symptoms reported by the workers

\begin{tabular}{|l|c|c|}
\hline Symptoms & Number & In percentage \\
\hline Persistent cough & 20 & 28 \\
\hline Breathlessness during work & 10 & 14 \\
\hline Wheezing & 8 & 11 \\
\hline Dizziness & 10 & 14 \\
\hline Burns to skin or eyes & 10 & 14 \\
\hline Irritant to skin/eyes/nose & 28 & 39 \\
\hline Fatigueness/ tiredness & 22 & 31 \\
\hline Head ache & 24 & 33 \\
\hline
\end{tabular}




\section{Discussion}

The available data shows that most of them were in the desirable BMI rate. This is because that their nature of work demands thin or moderately built people. The age below 40 comprises $62.5 \%$ of workers. Seventy two per cent have more than 10 years of exposure. In another study half $(50.5 \%)$ of spray painters was between 25 and 34 years of age ${ }^{[9]}$.

Organic solvents may be absorbed via inhalation, ingestion, and transdermal routes of exposure. Fifty three percent have inhalation related symptoms (persistent cough, breathlessness during work, wheezing etc). Fifty three percent have dermal related symptoms like burns to skin or eyes and irritant to skin/eyes/nose. Head ache $33 \%$, tiredness $31 \%$ and dizziness $14 \%$ may be the symptoms due to ingestion $(78 \%)$.

It is reported that majority $(85.7 \%)$ of the spray painters confirmed to have experienced the bronchitis related symptoms, while a big number $(67.3 \%)$ of them experienced asthmatic related symptoms. Eye problems $(49.2 \%)$ are not as prevalent as asthmatic and bronchitis symptoms ${ }^{[9]}$. These observations are in concordant with the present study. Other studies have reported similar observations among workers exposed to cement in construction sites ${ }^{[10.11]}$.

The symptoms reported by this study group highlight the need for a detailed and exploratory study on this type of occupational exposure. Most of them are using face masks. However, the ingestion is a prominent way of entering this harmful substance into the body. Dermal route is also in a high. The study suggests that the workers in spray paint industry are at the risk of developing a lot of occupational health issues. The precautions that they take now are not enough.

\section{Acknowledgement}

Financial supports by UGC, Govt of India as a minor research project vide MRP(S)-1360/11-12/ KLCA 020/ UGC-SWRO dt 10.07.2012 to the first author while working at St Aloysius College, Elthuruth, Thrissur, Kerala, India is gratefully acknowledged.

\section{References}

[1]. Turner, G P (1980). Introduction to Paint Chemistry and Principles Paint Technology.2 ${ }^{\text {nd }}$ Ed Londan-New York, Chapman and Hall 108-134.

[2]. Piña-Calva A., Madrigal-Bujaidar E., Fuentes M. V., Neria P., Perez-Lucio C. and Velez-Zamora N. M, Increased Frequency of Chromosomal Aberrations in Railroad Car Painters, Archives of Environmental Health: An International Journal, 46 (6). 1991, 335-339.

[3]. Dupont J, On the solid, liquid and solution structural organization of imidazolium ionic liquids, Journal of the Brazilian Chemical Society. 15 (3), 2004, 341-350.

[4]. Cohr KH, Uptake and distribution of common industrial solvents, Prog Clin Biol Res, 220, 1986, 45-60.

[5]. Temel, O., Sakar Coskun, A., Yaman, N., Sarioglu, N., Alkaç, C., Konyar, I and Yorgancioglu A, Occupational asthma in welders and painters. Tuberk Toraks, 58(1), 2010, 64-70.

[6]. Mose, A. P., Lundov, M. D., Zachariae, C., Menné, T., Veien, N. K., Laurberg, G.and Mortz, C. G., Occupational contact dermatitis in painters-an analysis of patch test data from the Danish Contact Dermatitis Group, Contact Dermatitis, 67(5), 2012, $293-297$.

[7]. Kelafant, G. A., Berg, R. A., \& Schleenbaker, R, Toxic encephalopathy due to 1, 1, 1-trichloroethane exposure. American journal of industrial medicine, 25(3), 1994, 439-446.

[8]. Biscaldi, G. P., Mingardi, M., Pollini, G., Moglia, A., \& Bossi, M. C., Acute toluene poisoning. Electroneurophysiological and vestibular investigations. Toxicological European research. Recherche europeenne en toxicologie, 3(6), 1981, $271-273$.

[9]. Mwatu, A. K., Hazards associated with spray painting among workers in small scale auto garages in Embakasi Division, Nairobi, Kenya, Doctoral diss , Kenyatta University, 2011.

[10]. Saji K.G., Sreelatha B.Nair, Deepthi Venugopal and Varghese P.R., Health hazards in cement workers - an epidemiological study, Scientia 8 (1),2012, 140-144.

[11]. Saji K G and Varghese P R, An Epidemiological Study on Health Status of Cement Workers. Int. J of Science and Research,.3 (10), 2014, 318-320. 